\title{
DRUG UTILIZATION STUDY IN OUTPATIENT DEPARTMENT OF PAEDIATRICS OF TERTIARY CARE HOSPITAL
}

Zenifer Khan', Parag Sharma², Rituja Kaushal ${ }^{3}$, Jytosna Verma ${ }^{4}$

1 Post Graduate Student, Department of Pharmacology, L. N Medical College \& Research Center, Bhopal, Madhya Pradesh. 2 Professor and HOD, Department of Pharmacology, L. N Medical College \& Research Center, Bhopal, Madhya Pradesh.

${ }^{3}$ Assistant Professor, Department of Preventive and Social Medicine, L. N Medical College \& Research Center, Bhopal, Madhya Pradesh. ${ }^{4}$ Assistant Professor, Department of Paediatrics, L. N Medical College \& Research Center, Bhopal, Madhya Pradesh.

\section{ABSTRACT}

\section{BACKGROUND}

Children constitute a large proportion of total population in developing countries. They are prone for moderate-to-severe illness and more vulnerable to various adverse effects related to drug used, so it is important to study drug utilization pattern in paediatrics population.

\section{OBJECTIVE}

To analyse drug utilization among Paediatric Outpatient Department and to assess the prescriptions for WHO recommended prescribing indicators.

\section{MATERIAL AND METHODS}

This study is a cross-sectional, analytical study. It was carried out in Department of Paediatrics at J. K. Hospital, Bhopal, M.P. over a period of 3 months involving all children up to 12 years of age attending the Paediatrics OPD during the study period.

\section{RESULTS}

Total of 320 patients up to 12 years of age prescriptions were analysed, which includes $55 \%$ male and $45 \%$ female. Total 890 medicines prescribed were analysed, in which $85.0 \%$ of medicines were prescribed from hospital formulary. The most common medicine prescribed was paracetamol 26.4\%, antibiotics $21.2 \%$ and bronchodilator were $19.2 \%$. Average number of drugs prescribed per prescription was $2.7 \pm 0.8$. Most common antibiotic prescribed was amoxicillin with clavulanic acid in $22.3 \%$ patients. Medicines prescribed by generic name were $71.6 \%$. Oral route of drug administration was common in $80.5 \%$.

\section{CONCLUSION}

On assessing the WHO indicators in the present prescription audit provided information about the problems and faults in the current practice. The percentage of drugs prescribed by generic name, percentage of antibiotic and injections prescribed were less. However, there was overprescribing of drugs to the outpatients that need a special attention of all doctors and clinical pharmacists to work together to establish a rational protocol for clinical use of drugs.

\section{KEYWORDS}

Drug Utilization, Paediatrics, Rational Drug Use, Prescribing Indicators.

HOW TO CITE THIS ARTICLE: Khan Z, Sharma P, Kaushal R, et al. Drug utilization study in outpatient department of paediatrics of tertiary care hospital. J. Evolution Med. Dent. Sci. 2016;5(26):1372-1375, DOI: 10.14260/jemds/2016/323

\section{INTRODUCTION}

Paediatrics population contribute about $40 \%$ of total Indian population. ${ }^{1}$ Children suffer frequently from various illnesses like acute respiratory infections, acute diarrhoea, viral fever, typhoid, malaria, etc. which account for major proportion of paediatric OPD visit. ${ }^{2}$ The rational use of drugs require the patient to receive medicines appropriate to their needs in doses that meet their individual requirement for adequate period of time and at lowest cost. ${ }^{3}$ Medically inappropriate, ineffective, non-economic use of pharmaceutical product is commonly observed in health care system throughout the world and especially so in developing countries. ${ }^{4}$

Financial or Other, Competing Interest: None.

Submission 12-02-2016, Peer Review 09-03-2016,

Acceptance 15-03-2016, Published 31-03-2016.

Corresponding Author:

Dr. Zenifer Khan,

D-22 Vardhman Green Park,

Ashoka Garden, Bhopal,

Madhya Pradesh.

E-mail: doc.zeniferkhan@gmail.com

DOI: $10.14260 /$ jemds $/ 2016 / 323$
Inappropriate prescription not only increases the cost of medical treatment, but also increases the morbidity and mortality.

In order to have the concept of essential drug program to promote rational drug use, WHO published its report on selection of essential drugs in 1977.5 World Health Organization (WHO) has formulated a set of core drug use indicators which measure the performance of prescribers, patients experience at health facilities and whether the health personnel can function effectively. ${ }^{6}$

Prescription audit study in a particular setting given an idea about the prescribing practices and signals of irrational drug use. With the help of WHO prescribed drug use indicators it is possible to compare drug utilization patterns between different settings prescription audit play a significant role in helping the healthcare system to understand, interpret and improve use of medications.

The irrational use of drugs is known to an increase in the cost of treatment and adverse drug reactions. Various drug utilization studies have been carried out all over the world, but there are limited studies addressing drug use in paediatric population in India. 
The objectives of this study are to assess the prescribing patterns of medicines and to assess the prescriptions on WHO recommended prescribing indicators.

\section{MATERIAL AND METHODS}

A cross-sectional, analytical study was conducted at J. K. Hospital, Bhopal, M.P., in the Department of Paediatrics. All children below 12 years attending the paediatric OPD were included in the study. The duration of the study was 3 months. So out of 12 months, at random 3 consecutive months from September to November 2015 were chosen for the study. Each and every patient fitting in our study criteria was enrolled in this duration. Total 320 patient's prescription were collected in and were analysed. Ethical clearance was accorded by Institutional Ethical Committee before starting the study. Informed content was taken from the parents of the children before enrolling in the study.

Referral prescriptions and prescriptions of seriously ill patient were excluded from study. The names of patient and prescribing doctors were kept confidential throughout the study. Predesigned, pretested, semi-structure proforma was used for data collection. All the drugs prescribed were recorded including each drug dosage, route and dosage form, frequency of administration, indication for which the drug was prescribed and duration of therapy. Necessary data were obtained from a total 320 prescriptions and analysed for following indicators.

1. Demographic characteristics of patients.

2. Number of medicines per prescription.

3. Percentage of Medicines prescribed by hospital pharmacy.

4. Percentage of medicine prescribed by essential medicine list.

5. Percentage of antibiotic prescribed.

6. Route of drug administered.

7. Percentage of drug prescribed by generic name.

Data entered in Microsoft Excel sheet and analysed with the help of statistical software SPSS Version 16. Mean and percentage were used for statistical analysis.

\begin{tabular}{|c|c|c|c|}
\hline $\begin{array}{c}\text { Age of } \\
\text { Patient in } \\
\text { Years }\end{array}$ & $\begin{array}{c}\text { Number and } \\
\text { Percentage } \\
\text { of Patient }\end{array}$ & $\begin{array}{c}\text { Number } \\
\text { and } \\
\text { Percentage } \\
\text { of Males }\end{array}$ & $\begin{array}{c}\text { Number and } \\
\text { Percentage } \\
\text { of Females }\end{array}$ \\
\hline 0 - 2 years & $86(26.9 \%)$ & $49(15.3 \%)$ & $37(11.5 \%)$ \\
\hline 2 - 5 years & $127(39.7 \%)$ & $71(22.1 \%)$ & $56(17.5 \%)$ \\
\hline 5 - 8 years & $76(23.7 \%)$ & $39(12.1 \%)$ & $37(11.6 \%)$ \\
\hline $8-12$ years & $31(9.7 \%)$ & $17(5.31 \%)$ & $14(4.4 \%)$ \\
\hline Total & $\mathbf{3 2 0 ( 1 0 0 \% )}$ & $\mathbf{1 7 6}(\mathbf{5 5 \% )}$ & $\mathbf{1 4 4}(\mathbf{4 5 \% )}$ \\
\hline
\end{tabular}

Table 1: Demographic Characteristics of Patients

\begin{tabular}{|c|c|c|}
\hline $\begin{array}{c}\text { Number of Drug per } \\
\text { Prescription }\end{array}$ & $\begin{array}{c}\text { Number of } \\
\text { Patients }\end{array}$ & $\begin{array}{c}\text { Percentage of } \\
\text { Patient }\end{array}$ \\
\hline 1 & 39 & $8.1 \%$ \\
\hline 2 & 102 & $32.5 \%$ \\
\hline 3 & 112 & $36.2 \%$ \\
\hline 4 & 24 & $8.4 \%$ \\
\hline 5 & 30 & $10.3 \%$ \\
\hline 6 & 11 & $4.3 \%$ \\
\hline \multicolumn{2}{|l}{ Table 2: Average Number of Medicine per Prescription } \\
\hline
\end{tabular}

J. Evolution Med. Dent. Sci./ eISSN- 2278-4802, pISSN- 2278-4748/ Vol. 5/ Issue 26/ Mar. 31, 2016
DRUG PRESCRIBED BY PHARMACY
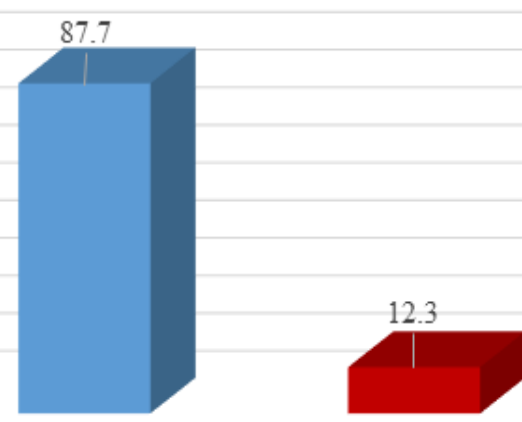

HOSPITAL PHARMACY

NOT FROM HOSPIT AL PHARMACY

Fig. 1: Percentage of Medicine Prescribed from Hospital Pharmacy

\begin{tabular}{|c|c|}
\hline Drug Category & Percentage \\
\hline Paracetamol & $26.4 \%$ \\
\hline Antibiotics & $21.2 \%$ \\
\hline Bronchodilators & $19.3 \%$ \\
\hline Vitamin & $17.6 \%$ \\
\hline Cough suppressant & $8.3 \%$ \\
\hline Anti-histaminic & $3.6 \%$ \\
\hline Nasal decongestant & $1.8 \%$ \\
\hline Anti-epileptics & $1.7 \%$ \\
\hline Table 3: Percentage of Drug Prescribed from Essential \\
Medicine Drug List \\
\hline
\end{tabular}

\begin{tabular}{|c|c|}
\hline Drug Category & Percentage \\
\hline Paracetamol & $26.4 \%$ \\
\hline Antibiotics & $21.2 \%$ \\
\hline Bronchodilators & $19.3 \%$ \\
\hline Vitamin & $17.6 \%$ \\
\hline Cough suppressant & $8.3 \%$ \\
\hline Anti-histaminic & $3.6 \%$ \\
\hline Nasal decongestant & $1.8 \%$ \\
\hline Anti-epileptics & $1.7 \%$ \\
\hline \multicolumn{2}{|c|}{ Table 4: Percentage of Drug Prescribed } \\
from Essential Medicine Drug List
\end{tabular}

\begin{tabular}{|c|c|c|}
\hline $\begin{array}{c}\text { Name of } \\
\text { Drug }\end{array}$ & $\begin{array}{c}\text { Number of } \\
\text { Patients }\end{array}$ & $\begin{array}{c}\text { Percentage of } \\
\text { Patient }\end{array}$ \\
\hline $\begin{array}{c}\text { Amoxicillin }+ \\
\text { Clavulanic acid }\end{array}$ & 57 & $22.3 \%$ \\
\hline Cefixime & 39 & $15.2 \%$ \\
\hline Metronidazole & 37 & $14.4 \%$ \\
\hline Cefadroxil & 31 & $12.1 \%$ \\
\hline Ceftriaxone & 29 & $11.4 \%$ \\
\hline Amikacin & 25 & $9.76 \%$ \\
\hline Ofloxacin & 21 & $8.2 \%$ \\
\hline Azithromycin & 17 & $6.6 \%$ \\
\hline \multicolumn{2}{|c|}{ Table 5: Percentage of Antimicrobial Prescribed } \\
\hline
\end{tabular}




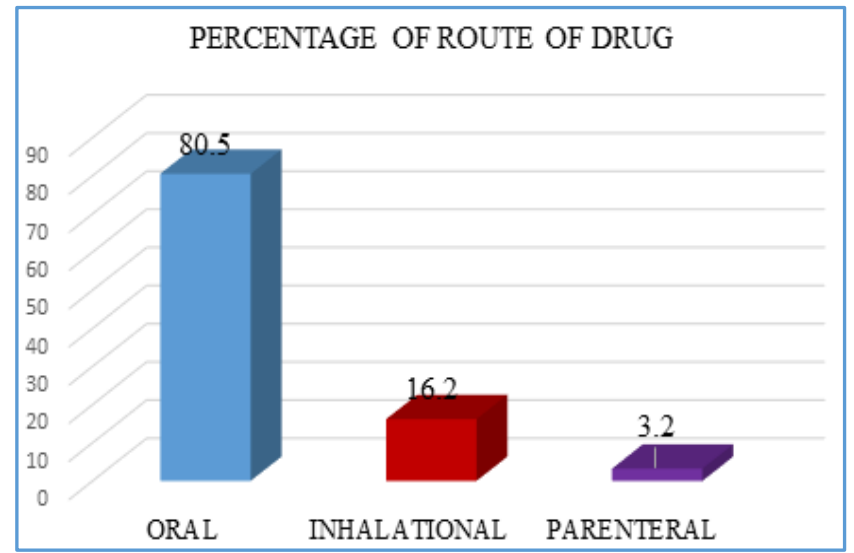

Fig. 2: Route of Drug Administered

\section{PERCENTAGE OF DRUG PRESCRIBED}

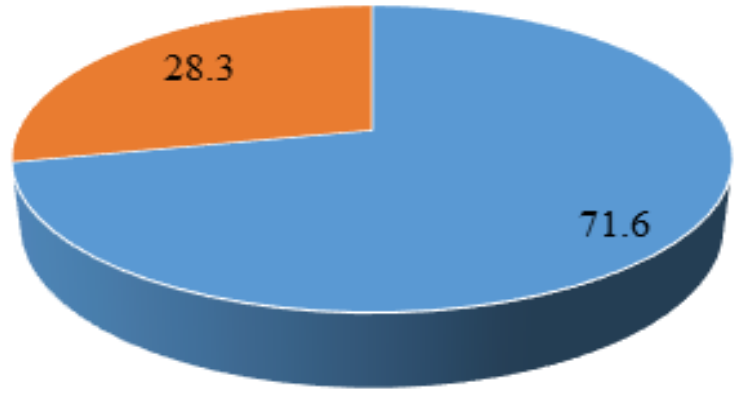

- generic name $\quad$ brand name

\section{Fig. 3: Drug Prescribed by Generic Name}

\section{RESULTS}

A total of 320 paediatrics outpatients up to 12 years of age were enrolled in the study. Out of 320 patients, 55\% were males and $45 \%$ females. Age distribution shows most of the patients were between 2-5 years old with the percentage of $39.7 \%$ followed by $0-2$ years $26.9 \%$ and $5-8$ years $23.7 \%$. The mean age of outpatients for male and female were found to be $4.33 \pm 0.30$ and $4.14 \pm 0.49$ (Table 1). Total 890 medicines were prescribed to total 320 patients, out of which $36.2 \%$ (116) patients were prescribed 3 medications, 32.4\% (104) patients were prescribed 2 medications and $10.3 \%$ (33) patients got 5 medications. Many drugs were prescribed in various combinations in most of the patients like amoxicillin with clavulanic acid, multivitamins, antihistamines with bronchodilators and cough suppressants with antihistamines. Combination drug treatment is common in paediatric patients. Most common prescribed combination is antihistamines with bronchodilator. It provides synergistic effect to the patient and decrease side effects. Only $4.3 \%$ (14) patients got 6 medications (Table 2).

Out of total 890 medicines, $87.7 \%$ (781) drugs were prescribed from hospital pharmacy and $12.3 \%$ (109) were not prescribed from hospital pharmacy (Figure 1). Out of total medicines prescribed to 320 patients, paracetamol was most commonly prescribed medicine in $26.4 \%$ patients, antibiotics were the second most commonly prescribed in $21.2 \%$ followed by bronchodilators in $19.3 \%$, vitamins in $17.6 \%$ patients. Antiepileptics were least commonly prescribed in $1.7 \%$ patients (Table 3 ).

Among 8 antimicrobial prescribed, amoxicillin with clavulanic acid was most commonly prescribed in $22.3 \%$ patients followed by cefixime in $15.2 \%$, metronidazole in $14.4 \%$ and azithromycin was least prescribed in $6.6 \%$ (Table 4). Total 3 routes of drug administration were used, about $80.5 \%$ patients received oral route, $16.2 \%$ received inhalational route and $3.2 \%$ received parenteral route $(\mathrm{I} / \mathrm{V}$ and I/M) (Figure 2). Out of total 890 medicines, 71.6\% (638) were prescribed by generic name and $28.3 \%$ (252) by brand name (Figure 3).

\section{DISCUSSION}

The results of the present study were based on the data obtained from 320 patients. Out of 320 patients, most of the patients were male $55 \%$ followed by female patients $45 \%$. Our results were similar to the studies conducted by Dinesh et al., and Karande et al. ${ }^{7,8}$

The more number of paediatric patients belongs to age group 2-5 years $(39.7 \%)$ and next in $0-2$ years $(26.9 \%)$. This indicates more chances of infections in 2-5 years' age group. Choudhury DK. ${ }^{9}$ study shows more patients belong to 5-12 years. In the present study on an average 3.42 medicines were prescribed per patient, which is much higher when compared with 2.9 and 2.07 in similar studies from Karande et al. and Dinesh et al. 7,8

WHO recommends that the average number of drugs per prescription should be less than two. ${ }^{9}$ We also found that more than half of patients were given three or more medicines. Thus, it is evident that the polypharmacy and over prescribing are common in India. In present study, $98.1 \%$ of drugs were prescribed from the WHO list of essential medicines 2013 and this is more compared to Kanish et al. study. ${ }^{10}$ Drug prescription from essential list of medicines is beneficial in terms of cost effectiveness and safety of the drugs. ${ }^{9}$

In present study, $21.2 \%$ of antibiotics were prescribed which was slightly near to the WHO recommended range of 20-26\% and this percentage is less compared to Kanish et al. study. ${ }^{10}$ and more compared to Shankar et al. study. ${ }^{1}$

Most common antibiotic prescribed was amoxicillin with clavulanic acid (22.3\%) and cefixime was the second most common antibiotic (15.2\%), likewise ceftriaxone and amikacin prescribed in most of the infectious diseases like URTI, bronchiolitis, pneumonia. While ofloxacin was the commonly prescribed drug for acute diarrhoea and acute dysentery. This result was comparable with other studies like Choudhury DK. ${ }^{11}$ and Kanish et al. ${ }^{10}$

In our study, $71.4 \%$ medicine were prescribed from generic name prescribing by generic name is known to reduce the cost of drug treatment and rationalizing drug therapy. This varies from $13.3-93 \%$ across the globe. The results of work conducted in India report this as $73.4 \% .{ }^{12}$ which was compare very well with the Figure $(71.3 \%)$ found in this study. One of the reasons for poor prescribing by generic name is the nonavailability of the paediatric formulations in the hospital pharmacy. Hence, clinicians often prefer to prescribe by trade names with which they are familiar and the patients find it easier to procure.

\section{CONCLUSION}

To conclude, this study provides few insights into the drug use patterns in paediatric outpatient department of a tertiary care 
teaching hospital. The drug prescribing from NLEM was fair, creating awareness of essential medicine concept.

This study revealed that polypharmacy and prescription by brand name were common. Use of 'generic name' in the prescriptions needs to be promoted. An increasing in the percentage of patients knowing correct dosage schedule will improve the present health care of patients attending paediatric department of hospital. Continuous prescription audits, medical education with a focus on rational drug use and evidence based medicine should be the policy of hospital.

Better prescribing practices as suggested above would lead to improvement in quality of health care provided to children. Educational interventions towards improving prescribing practices are required.

\section{ACKNOWLEDGEMENTS}

I would like to express my deepest sincere gratitude to my honourable teachers and esteemed guide Dr. Parag Sharma, MD, Professor and Head of the Department of Pharmacology. Dr. Jyotsna Verma, MD, Assistant Professor, Department of Paediatrics and all staff of Department of Pharmacology, L. N. Medical College and Research Center, Bhopal, M.P.

\section{REFERENCES}

1. Shankar PR, Upadhyay DK, Subish P, et al. Prescribing patterns among paediatric inpatients in a teaching hospital in western Nepal. Singapore Med J 2006;47(4):261-265.

2. Shamshy K, Mufida B, Perumal P. Drug utilization of antimicrobial drug in pediatrics population in a tertiary care hospital in erode, Tamilnadu, India. International Journal of Pharm Teach Research 2011;3(3):1530-1536.

3. Ansari KU, Singh S, Pandey RC. Evaluation of prescribing pattern of doctors for rational drug therapy. Indian J Pharmacol 1998;30(1):43-46.
4. Melrose D. Double deprivation public and private drug distribution from the perspective of the third world's poor. World Dev 1983;11(3):181-6.

5. Cazzato T, Pandolfini C, Campi R, et al. Drug prescribing in out-patient children in southern Italy. Eur J Clin Pharmacol 2001;57(8):611-616.

6. Akhtar MS, Divya V, Pillai K, et al. Drug prescribing practices in paediatric department of a northindian university teaching hospital. Asian J Pharm Clin Res 2012;5:146-9.

7. Dinesh KG, Padmasani L, Vasantha J, et al. Drug prescribing pattern among pediatricians in an outpatient department of tertiary care teaching hospital. Indian J Pharm Pract 2011;4:64-8.

8. Karande S, Sankhe P, Kulkarni M. Patterns of prescription and drug dispensing. Indian J Pediatr 2005;72:117-21.

9. WHO. How to investigate drug use in health facilities: selected drug use indicators, Geneva: World Health Organization 2010:WHO/DAP/93.

10. Kanish Ravika, Gupta Kanchan, Juneja Shivani, et al. Prescribing pattern of antibiotics in the department of paediatrics in tertiary care medical college hospital in northern India. Asian Journal of medical sciences 2014;5(4):69-72.

11. Choudhury DK, Bezbaruah BK. Antibiotic prescriptions pattern in paediatric in-patient department guwahati medical college and hospital, guwahati. Journal of Applied pharmaceutical science 2013;3(8):144-148.

12. Cazzato T, Pandolfini C, Campi R, et al. Drug prescribing in out-patient children in Southern Italy. Eur J Clin Pharmacol 2001;57(8):611-616. 